\title{
Liberalismo ou Desenvolvimentismo Associado? Uma Interpretação da Política Econômica do Governo Dutra (1946-1950)
}

\section{Liberalism or Associated Developmentalism? An Interpretation of Dutra's Economic Policy (1946-1950)}

\author{
Leonardo Staevie Ayres* \\ Pedro Cezar Dutra Fonseca**
}

\begin{abstract}
Resumo: O objeto deste artigo é discutir a política econômica do governo de Eurico Gaspar Dutra (1946-1950), em especial a controvérsia da literatura sobre o tema, polarizada na questão de se pode ser considerada continuidade ou ruptura com relação ao projeto de industrialização por substituição de importações presente na economia brasileira desde a década de 1930. Para tanto, defende-se que há evidências de continuidade com relação às políticas desenvolvimentistas. Em adição, argumenta-se que não se trata de liberalismo ou ortodoxia, como defende parte da literatura, mas de outro estilo ou padrão de desenvolvimento, diferente do nacional-desenvolvimentismo de Vargas, mais favorável aos investimentos externos e a maior integração à economia internacional. Nesse sentido, conclui-se que o governo Dutra, embora represente uma continuidade com relação à industrialização, prenuncia ou antecipa as políticas desenvolvimentistas mais tarde executadas no governo Kubitschek (1956-1960).
\end{abstract}

Palavras-chave: Governo Dutra. Substituição de importações. Desenvolvimentismo.

Abstract: There is a controversy on the literature about the Dutra administration economic policy (1946-50): whether it can be considered continuation or rupture in relation to the industrialization project through import substitution that took place in Brazil since the 1930s. Thus, we argue that there is evidence of continuity with respect to economic development policies. In addition, we also propose the debate should not be focused on "liberalism or orthodoxy", as other authors advocate, but on another style or pattern of developmentalism, different from Vargas' "national developmentalism", as Dutra was more favorable to foreign investment and greater integration to the international economy. In this sense, we conclude that the Dutra administration, although representing continuity with regard to industrialization, foreshadows or anticipates development policies later executed by the Kubitschek administration (1956-1960).

Keywords: Dutra administration. Economic development. Import substitution.

JEL Classification: N16; N46; O11; O23.

* $\quad$ Mestre em Economia pelo Programa de Pós-Graduação em Economia (PPGE) da Universidade Federal do Rio Grande do Sul (UFRGS). E-mail: leonardoayres12@hotmail.com

** Doutor em Economia pela Universidade de São Paulo (USP). Professor titular do Departamento de Economia e Relações Internacionais da Universidade Federal do Rio Grande do Sul (UFRGS). Pesquisador do CNPq. E-mail: pedro.fonseca@ufrgs.br 


\section{1 lntrodução}

A memória histórica do governo de Eurico Gaspar Dutra (1946-1950) consagra sua associação ao conservadorismo. Essa não deixa de ser também a percepção de seus coevos. Situado entre os dois governos de Vargas, a pergunta se seu governo representou mais ruptura do que continuidade com o de Vargas é inescapável em qualquer interpretação. No plano político, Dutra sempre representou uma figura menos carismática e mais conservadora: antes da Segunda Guerra, manifestara clara simpatia ao Eixo. A esquerda nunca perdoou o fato de, em seu governo, o Partido Comunista Brasileiro (PCB) ter sido declarado ilegal: embora por decisão do Judiciário, a medida contou com forte apoio de Dutra e dos políticos mais próximos a seu governo. Alçado a ministro da Guerra durante o Estado Novo, aderiu à causa dos Aliados, e a vitória credenciou-o a concorrer à Presidência da República pelo Partido Social Democrático (PSD), numa época em que o Partido Trabalhista Brasileiro (PTB) - o outro partido criado por Vargas, mais à esquerda do que o primeiro - ainda estava em processo de formação. Vargas, só na última semana antes da eleição, e após muita pressão, declarou seu apoio à candidatura de Dutra: "autoexilado" em São Borja desde sua deposição em 1945, sugeria não ver muita diferença entre Dutra e o brigadeiro Eduardo Gomes, o candidato da União Democrática Nacional (UDN). Aqui reside já a primeira demarcação da diferença entre ambos e que permaneceu por todo o período governamental: Vargas declarou-se oposição ao governo e, ao candidatar-se a sucessão, enfatizou que retomaria seu projeto de industrialização do país, que teria sido abandonado por Dutra (VARGAS, 1951; FONSECA, 1999).

A política econômica do governo Dutra também dá margem para alimentar a controvérsia. Tendo assumido numa conjuntura de relativa folga no balanço de pagamentos, decorrente da melhoria das relações de intercâmbio e da contenção das importações ocorridas nos últimos anos da guerra, seu governo promoveu inicialmente uma liberalização das importações. Tal medida incentivou a compra de bens de consumo, ocasionando a "queima de divisas" que poderiam ser utilizadas para a importação de bens de capital e insumos necessários à produção nacional. Vargas explorou já na campanha presidencial para sucedê-lo o seguinte fato: "Essas disponibilidades - no que tange às divisas - foram quase totalmente desbaratadas por uma política de gastos imoderados, de importações suntuárias e de criminoso resgate da dívida externa consolidada" (VARGAS, 1951, p. 23-24). Ademais, a euforia cambial tinha pés de barro: a liberalização do mercado cambial caíra numa "ilusão de divisas", uma vez que, do total de 730 milhões em haveres monetários, apenas 92 milhões eram em moedas conversíveis (MALAN, 1980, p. 165; SARETTA, 2000, p. 125). Assim, a situação rapidamente se reverteu, de eufórica para calamitosa, uma vez que os superávits comerciais eram obtidos com 
países de moedas inconversíveis, enquanto com os Estados Unidos a relação era deficitária. Deve-se considerar, em adição, que, com o acordo de Bretton Woods, o dólar passara a ser a moeda por excelência no comércio internacional.

Tudo sugere não haver muita dúvida na literatura quanto aos pendores liberalizantes do primeiro ano do governo Dutra, o que contrasta com o intervencionismo do Estado Novo. Almeida (1993, p. 13) assinala que o período governamental é normalmente considerado como um "[...] parêntese liberal numa longa era caracterizada pelo intervencionismo econômico [...]". Skidmore (1976, p. 96) chega a sustentar que a intenção do governo era retornar ao ideal das vantagens comparativas, embora, adiante, aponte que as decisões eram erráticas, em "zigue-zague". Bastos (2010), por sua vez, argumenta com propriedade que o clima liberalizante do pós-guerra fora realçado localmente com a pressão de grupos econômicos (como comerciantes, industriais e agraristas) para que o governo se envolvesse menos na economia, a chamada campanha liberal, iniciada ainda no Estado Novo. Assinala, também, que as primeiras ações liberalizantes começaram já no governo provisório de José Linhares e seu ministro José Pires do Rio, “[...] antes de serem aprofundadas no governo Dutra [...]" (BASTOS, 2004, p. 3).

A controvérsia ganha maior envergadura ao se analisarem os anos seguintes do período de Dutra. Vianna e Villela (2005) optam por reconhecer no governo duas fases. Na primeira, predominara a ortodoxia, sendo sucedida, principalmente após a substituição de Guilherme da Silveira por Correa e Castro, em 1949, por uma política com mais ênfase no crescimento, aos moldes desenvolvimentistas. Embora as mudanças na política econômica sejam frequentes em qualquer governo, inclusive por pressões de desequilíbrios de conjuntura ou de natureza política, não evitam a questão que indaga sobre sua orientação predominante ou intencionalidade. No caso do governo Dutra, em adição, como se mostrará adiante, não há evidências de duas fases bem demarcadas, embora haja elementos para sustentação de que o predomínio mais liberal do primeiro ano de governo tenha sido substituído por medidas mais intervencionistas e pró-crescimento nos anos seguintes. Assim, autores como Skidmore (1976), Furtado (1977), Lessa (1982) e Viana (1987), embora reconheçam em menor ou maior grau a não linearidade da política econômica, associam-na à ortodoxia. Defendem que o crescimento industrial verificado no período foi fruto de ações decorrentes de outros objetivos, como combate à inflação e correção dos déficits externos. Tal linha de interpretação aponta para o rompimento com o projeto de industrialização por substituição de importações iniciado no primeiro governo de Vargas. A literatura mais recente, entretanto, vem firmando a tese que questiona tal ponto de vista. Assim, Saretta (2000), Bresser-Pereira (2003), Bastos (2004, 2010) e Fonseca (2010) discordam do predomínio ortodoxo da política econômica e sustentam haver evidências de medidas voltadas ao crescimento industrial executadas conscientemente com esse fim. 
O presente artigo visa robustecer essa última linha de interpretação. Para tanto, trabalha-se com duas hipóteses. A primeira propõe que se pode associar a política econômica do governo Dutra a desenvolvimentismo. Para tanto, trata-se de identificar, com base na conceituação proposta por Fonseca (2014), o propósito do governo em promover o crescimento da economia com base no setor industrial, cabendo ao Estado um papel indutor, nesse aspecto não representando antagonismo maior com o projeto do governo anterior de Vargas. Já a segunda hipótese traz à liça a diferença entre os dois governos, pois propõe que na política econômica do governo Dutra há a gênese do projeto do desenvolvimentismo “dependente-associado". ${ }^{1}$ Ou seja: não se trata, a rigor, de liberalismo ou ortodoxia (embora esses termos envolvam, por si só, ampla discussão sobre seu significado), mas de outro estilo (PINTO, 1976), padrão (TAVARES, 1978; CARDOSO, 1971) ou subtipo (FONSECA, 2014) de desenvolvimento. Diferentemente do período Vargas, marcado pela contração do comércio internacional com a Grande Depressão e, depois, pela guerra, o governo Dutra pretendeu apostar no capital externo para alavancar o crescimento industrial, aproveitando-se da conjuntura favorável ao comércio internacional, com maior liquidez, fruto do acordo de Bretton Woods e da criação de instituições como o Banco Internacional para Reconstrução e Desenvolvimento (Bird) e o Banco Interamericano de Desenvolvimento (BID). Como corolário dessa hipótese, pode-se afirmar que o governo Dutra antecipa o "desenvolvimentismo internacionalizante" (AREND, 2009) de Juscelino Kubitschek (1956-1960), em contraste com o "nacional-desenvolvimentismo" varguista.

Além desta introdução, o artigo dedica duas seções para cada uma das hipóteses antes formuladas. A metodologia empregada é a análise dos discursos presidenciais, mensagens presidenciais, dados estatísticos acerca da composição do crédito e a parcela destinada à indústria, bem como de dados sobre investimentos

1 Segue-se aqui a tradicional tipologia uspiana, consagrada por autores como Florestan Fernandes, Octavio Ianni e Fernando Henrique Cardoso de apontar para dois projetos diferentes de desenvolvimentismo: o "nacional-desenvolvimentismo" e o "dependente-associado", o primeiro associado no Brasil a Vargas e o segundo a Kubitschek. Num esforço de síntese, primeiro, de caráter mais nacionalista, propunha maior papel ao Estado para alavancar recursos e realizar investimentos e centrava-se na produção de bens de consumo populares, liderado pelo setor privado nacional, bem como propunha avançar a industrialização da década de 1950 para os bens de capital e intermediários. Politicamente, o projeto contava para sustentação uma aliança entre esse empresariado, segmentos das "classes médias" (nestes incluída a burocracia) e trabalhadores urbanos, propondo a incorporação das massas, cuja expressão política seria o populismo. Já o segundo assentar-se-ia nos investimentos externos, principalmente de grandes empresas oligopolistas, para alavancar um padrão de industrialização restritiva, pois, assentado na produção de bens duráveis de consumo e na indústria pesada, cuja demanda voltava-se às camadas de rendas mais altas, não excluía de vez o Estado nem as burguesias locais, mas estabelecia entre eles outro tipo de associação, numa relação de subordinação ou dependência ao capital estrangeiro. A rigor, as duas estratégias ou estilos de desenvolvimento decorriam da incapacidade ou fragilidade dos grupos empresariais privados latino-americanos para liderar o crescimento industrial, seja pela inexistência de conhecimento tecnológico, seja por baixa capitalização. No primeiro modelo, o ator principal seria o Estado, capaz de captar poupança forçada para bancar as necessidades de investimento ou financiamento; no segundo, o capital estrangeiro, através de investimentos diretos ou de financiamento - a poupança externa (ver CARDOSO, 1971; FONSECA, 2014). 
estrangeiros no Brasil, além da análise de decretos e leis. As principais fontes de pesquisa, além das secundárias, são os discursos de Vargas, as compilações realizadas por José Teixeira de Oliveira (1956), além das mensagens presidenciais (BRASIL, 1978).

\section{Desenvolvimentismo do Governo Dutra}

Os indicadores mais importantes e que dão margem à controvérsia sobre a política econômica do governo Dutra, como crescimento do PIB, inflação e balanço de pagamentos, estão sintetizados na Tabela 1.

Tabela 1 - Brasil: taxa de crescimento de indicadores macroeconômicos (1946-1951)

\begin{tabular}{ccccccc}
\hline Ano & $\begin{array}{c}\text { PIB } \\
\text { (\%) }\end{array}$ & $\begin{array}{c}\text { Produto } \\
\text { industrial } \\
\text { (\%) }\end{array}$ & $\begin{array}{c}\text { Contas da } \\
\text { União } \\
\text { (Cr\$ milhões) }\end{array}$ & $\begin{array}{c}\text { Crédito } \\
\text { real à in- } \\
\text { dústria } \\
\text { (\%) }\end{array}$ & $\begin{array}{c}\text { Inflação } \\
\text { RJ (\%) }\end{array}$ & $\begin{array}{c}\text { Moedas } \\
\text { conversi- } \\
\text { veis (\%) }\end{array}$ \\
\hline 1946 & 11,6 & 18,5 & -2.633 & - & 16,5 & 12,6 \\
1947 & 2,4 & 3,3 & 460 & 38 & 21,9 & 4,7 \\
1948 & 9,7 & 12,3 & 3 & 19 & 3,4 & 9,0 \\
1949 & 7,7 & 11,0 & -2.810 & 28 & 4,3 & 17,8 \\
1950 & 6,8 & 12,7 & -4.297 & 5 & 9,4 & 21,6 \\
1951 & 4,9 & 5,3 & 2.819 & - & 12,1 & $-8,7$ \\
\hline
\end{tabular}

Fonte: Abreu (1990, p. 388-415).

Como é possível observar, as taxas de crescimento do PIB e da produção industrial do período foram, em média, bastante altas, não sugerindo, na análise de dados ex post, um refluxo do crescimento ou recessão. Cabe indagar se elas resultam simplesmente do ciclo econômico, de uma conjuntura favorável, ou se havia um projeto ou intenção deliberada do governo visando sua consecução. Só nesse último caso se pode associá-la a desenvolvimentismo, ou seja, resultante, pelo menos em parte, de um projeto intervencionista consciente, com evidências empíricas de medidas deliberadas em favor da industrialização (FONSECA, 2014, p. 56). A análise a seguir sugere a existência de tais evidências, de modo a permitir a associação da política econômica do governo Dutra com o desenvolvimentismo. Inicialmente são analisados os documentos propostos nas conferências das classes produtoras $(1945,1949)$ e as mensagens presidenciais, respectivamente, pois permitem detectar, através dos debates e propostas, a consciência já presente na defesa da industrialização. A seguir, indo além do discurso ou do plano das intenções, são apresentados dados acerca da evolução da indústria e do crédito destinado ao setor. 
Um primeiro ponto que merece atenção refere-se aos anseios da classe industrial com relação à política econômica externados durante as conferências das classes produtoras realizadas em 1945 e 1949, nos municípios de Teresópolis (RJ) e Araxá (MG), respectivamente. Essas referências evidenciam que Dutra e sua equipe econômica tinham conhecimento dos apelos pelo reequipamento e desenvolvimento da indústria. Verificou-se que os empresários esperavam a ajuda do Poder Público ao revelar seus interesses à nova administração. O documento de Teresópolis é parte integrante da obra de Cunha (1946), e o de Araxá está contido em Carone (1980).

$\mathrm{Na}$ Carta de Teresópolis, uma das primeiras ideias expostas é a necessidade do crescimento da renda nacional como condição para proporcionar a melhor distribuição da riqueza. Para alcançar tal objetivo, era necessário amplo apoio estatal, pois "[...] o meio adequado para obtê-lo é o planejamento da ação nacional para melhor aproveitamento das fontes de produção agrícola e industrial, e nos setores dos transportes, energia e crédito" (CUNHA, 1946, p. 9). Ao tratar sobre a produção industrial:

Declaram as Classes Produtoras sua convicção de estarem o progresso e a estabilidade da economia nacional intimamente ligados à industrialização do país, pois esta, além de permitir o aumento da renda nacional, assegura a diversificação da produção, elemento indispensável a essa estabilidade e progresso. [...] Recomendam, pois, que o Estado estimule e oriente a industrialização do país, baseado em estudos dos fatores fundamentais - mercados, mão de obra, matéria prima, transporte e energia (CUNHA, 1946, p. 45, grifo nosso).

A citação anterior demonstra que nem todos os empresários compactuavam com os ideais da campanha liberal, pois tais documentos deixam explícito que requisitavam a participação do governo no fomento da economia. Além disso, diversos setores estratégicos da indústria aspiravam melhorias e investimentos, tais como rodovias, aeroportos e transporte fluvial. Pode-se, inclusive, depreender que não se tratava de intervenções pontuais em favor de um setor ou outro (o que não seria propriamente desenvolvimentismo, mas reivindicações particularistas), pois se defende a atuação do Estado como planejador e coordenador dos investimentos necessários para "[...] o melhor entendimento entre os atuais departamentos oficiais para a organização de um plano geral em bases nacionais e econômicas" (CUNHA, 1946, p. 41).

A indústria de base era considerada essencial para o desenvolvimento industrial brasileiro. Dessa forma, o documento recomendava "[...] particular atenção às indústrias basilares [...] metalurgia de primeira fusão e atividade de transformação dela decorrente deverão ser fomentadas com interesse" (CUNHA, 1946, p. 56). A atenção estatal deveria focar nessa última, pois era vista como fundamental para 
o atendimento das "[...] necessidades nacionais de alimentação, vestuário, habitação e higiene [...]” (CUNHA, 1946, p. 58).

A sequência da Carta de Teresópolis permite um paralelo com as políticas praticadas pelo governo Dutra nos anos seguintes. No documento havia a sugestão para a utilização das reservas em moedas estrangeiras no reequipamento dos transportes e da indústria em geral. Também é exposta a ideia do controle de importações para promover a continuidade do Processo de Substituição de Importações (PSI) através de licenças para as compras externas que deveriam dar “[...] especial consideração às necessidades do reequipamento da indústria e dos transportes [...]" (CUNHA, 1946, p. 79).

A Conferência de Araxá (1949) se trata da evolução e o fortalecimento das ideias lançadas em Teresópolis (1945), já que os requerimentos ao governo e o entendimento de seu papel como planejador e coordenador de investimentos para a indústria se apresentam mais ostensivamente, inclusive na questão do crédito para financiar tais atividades:

Recomenda: 1) seja estudada e adotada pelos Poderes Públicos uma política nacional de reequipamento das indústrias e de ampliação do parque industrial, como condição essencial do desenvolvimento econômico do país e do levantamento do nível de vida da população; 2) que, para esse fim, seja facilitada, por medidas fiscais e de incentivo, a importação de maquinário e bens de capital; 3) que seja estimulada e assistida, com facilidades fiscais e de crédito a longo prazo, a produção nacional de bens de capital destinada ao suprimento das necessidades de aparelhamento das fontes produtoras do país, e assim também estendidas essas facilidades às empresas em condições de promover o seu reequipamento utilizando a produção nacional (CARONE, 1980, p. 358-359, grifo nosso).

A citação contribui para ilustrar a busca pelo diálogo entre o governo e líderes do setor industrial acerca das dificuldades enfrentadas, as quais entendiam se antepor ao crescimento da indústria. Isso contrapõe a hipótese de que Dutra teria a intenção de retornar ao modelo agroexportador, ou que fosse avesso à "causa da indústria". Destarte, sugere ser muito simplista argumentar que o crescimento da indústria fora acidental e que o governo não conhecia o alcance da política econômica implementada.

Outras cinco recomendações contidas no documento ainda contribuem para refutar a ideia de que o desejo dos empresários era, exclusivamente, a não intervenção do Estado na economia, salientando uma característica do Brasil, onde a tarefa de promover as transformações das relações econômicas vigentes cabia ao Poder Público, e não à burguesia, como nas sociedades europeias (SARETTA, 2000). As classes produtoras recomendavam a adoção de medidas fiscais, cambiais e políticas de crédito que conferissem tratamento especial às indústrias consideradas indispensáveis à aceleração econômica, como de máquinas, químicos, 
aço, ferro e combustíveis. Não obstante, os empresários também requeriam a participação do governo para obtenção de empréstimos internacionais de forma a financiar o reequipamento industrial (CARONE, 1980, p. 359-360).

A facilidade para a importação de máquinas e matéria-prima básica foi uma política do governo, que utilizaria o câmbio como principal instrumento para atender às reivindicações que se coadunavam com os objetivos do governo. Havia, também, uma visão de longo prazo traduzida na criação de linhas de crédito com taxas de juros especiais (mais adiante será demonstrado que o Banco do Brasil alavancou as liberações de recursos destinadas à indústria) e através do planejamento e criação de centros de pesquisa. Essa parceria entre governo e iniciativa privada visava, principalmente, o melhor aproveitamento de recursos naturais internos, associada a uma busca pela melhora nas condições de vida dos trabalhadores, já que a sua valorização e capacitação acelerariam o desenvolvimento industrial. Ademais, apelava-se para a especialização da mão de obra através de entidades públicas e privadas para fornecer treinamento profissional. Outro interesse do empresariado era que o Estado também promovesse a descentralização dos novos investimentos produtivos no Brasil:

[...] o desenvolvimento da industrialização no país deve obedecer, tanto quanto possível e o permitirem as conveniências geoeconômicas, ao critério da descentralização. [...] a localização de novas indústrias carece ser orientada no sentido do interesse econômico e social das regiões e dos Municípios, sem perder de vista o princípio da unidade econômica nacional (CARONE, 1980, p. 363).

Os documentos destacados contribuem para demonstrar o conhecimento do governo quanto aos anseios da classe industrial por uma política de desenvolvimento ao setor, e boa parte se coaduna com a política efetivamente empregada por Dutra, conforme seus discursos e os dados estatísticos demonstram. A intencionalidade do governo de continuar a substituição de importações está contida em pronunciamentos e mensagens presidenciais, os quais robustecem a interpretação segundo a qual havia consciência quanto às políticas e medidas implementadas.

A primeira mensagem presidencial de Dutra foi publicada em 15 de março de 1947. Ao longo do texto, ao tratar sobre a indústria nacional, o presidente faz ressalvas sobre o setor de transportes, cujos custos estariam muito altos devido ao aparelhamento defasado e pouco eficiente. Dutra salienta os problemas herdados da guerra e que prejudicavam a importação de bens essenciais como: combustíveis, alimentos, equipamento industrial e de transportes. Além disso, o presidente apontava a inflação como um dos principais problemas econômicos e lembra que o primeiro ano do seu governo fora dedicado à estabilização de preços através da redução do meio circulante e corte de gastos públicos. 
Outra preocupação era com a oferta de bens básicos ao mercado interno, principalmente itens de alimentação. Dessa forma, o governo incentivou a produção de gêneros alimentícios e matérias-primas de origem extrativa e agropecuária no sentido de tomar providências focando no longo prazo, através da criação de núcleos agroindustriais em terras públicas.

Quanto aos saldos congelados nos Estados Unidos e Grã-Bretanha, a estratégia do governo era utilizá-los, principalmente, para financiar o reaparelhamento da indústria e melhoria da infraestrutura adquirindo "[...] equipamentos e máquinas, tão vitalmente necessários ao reaparelhamento dos nossos portos, vias e meios de transporte, à mecanização da agricultura, à ampliação e modernização da nossa indústria" (BRASIL, 1978, p. 53).

Baer (1966) considera que o esforço industrializante ocorrido ao fim da guerra foi resultado da decisão política de utilizar o progresso industrial para transformar a estrutura econômica brasileira. Dessa forma, "[...] os responsáveis pelo país [...] se tornaram conscientes de que, no futuro, o Brasil não poderia alcançar elevado ritmo de crescimento se continuasse a se apoiar basicamente na exportação de seus principais produtos primários [...]" (BAER, 1966, p. 35). Além disso, a redução nas importações de bens de consumo manufaturados foi uma medida orientada aos moldes do PSI, em um momento de redução na importância relativa do comércio externo para o país.

O segundo ano de mandato (1947) é avaliado na mensagem presidencial de 15 de março de 1948 em documento que apresenta as realizações do governo na economia nacional com superávit orçamentário de 460 milhões de cruzeiros, além da redução da emissão monetária.

A sequência do texto remete à necessidade do crescimento da industrialização brasileira. Nota-se o embrião do Plano Salte, quando da escolha do governo de priorizar saúde, alimentação, transporte e energia - além do petróleo -, considerados fundamentais para ancorar o desenvolvimento econômico e social do Brasil. Esse era um plano quinquenal com investimento total estimado em $\mathrm{Cr} \$ 19,9$ bilhões, sendo Cr\$ 11,4 bilhões para os transportes, $\operatorname{Cr} \$ 3,2$ bilhões para a energia, Cr\$ 2,7 bilhões para a produção alimentícia e Cr\$2,6 bilhões para a saúde (BAER, 1966, p. 63).

Os recursos da nossa exportação são insuficientes. Ou procuramos outras fontes de exportação, ou havemos de substituir os nossos acréscimos de compra com produção nacional, evitando, desse modo, o aumento crescente da importação. Não é possível escolher, com exclusividade um ou outro caminho. Não há dúvida, porém, sobre a conveniência e urgência de dotar o país de meios para incrementar a produção de energia e da exploração do petróleo, cuidando simultaneamente da saúde e da alimentação do homem brasileiro. Saúde, alimentação, transporte, energia e petróleo - são as balizas que devem orientar o nosso esforço de recuperação (BRASIL, 1978, p. 69). 
As mensagens presidenciais de 1946 e 1947, período considerado de política econômica ortodoxa por autores como Furtado (1977), Lessa (1982) e Vianna (1987), permitem identificar diversas tentativas de dirigismo e planejamento para a economia brasileira. Há uma preocupação do governo em fortalecer a infraestrutura, além da intenção de criar condições para a importação de bens de capital para renovação da indústria, principalmente através dos controles cambiais e dos licenciamentos de importações. Entende-se que a exploração do petróleo e o desenvolvimento de uma indústria petrolífera nacional gerariam encadeamentos positivos para a economia como um todo, além de colaborar para a salvaguarda dos recursos naturais e da propriedade nacional, o que vai ao encontro das políticas desenvolvimentistas do período de Vargas.

Na sequência do mandato de Dutra, passa-se ao ano de 1948, cuja análise é retratada na mensagem presidencial de 15 de março de 1949. Nesse trecho há interesse no desenvolvimento energético do Nordeste, sendo a escassez de energia um dos principais fatores para a baixa produtividade e os reduzidos índices de desenvolvimento social, da região. Além disso, o governo almejava diminuir as desigualdades econômicas regionais, bem como combater dificuldades de saúde e educação no interior do Brasil.

Atrelado aos planos mencionados, o governo planejava a ligação rodoviária do país, fortalecendo a infraestrutura e criando mais condições favoráveis ao desenvolvimento industrial. Seriam promovidas as construções de trechos entre a capital federal, Salvador e Porto Alegre, juntamente com a Rio-São Paulo e a conexão ferroviária Norte-Sul. Ao tratar sobre o transporte hidroviário, Dutra ressalta os investimentos feitos no Porto do Rio de Janeiro, ampliando a área útil e renovando as máquinas e equipamentos.

A mensagem presidencial de 1948 também denota o interesse do governo em continuar projetos iniciados durante a administração Vargas. O rompimento com o projeto desenvolvimentista, calcado na expansão da indústria, não era uma tônica do governo Dutra. Este, a despeito das manifestações críticas de Vargas, procurava, ao contrário, salientar sua postura de continuidade das obras iniciadas antes de seu mandato, inclusive com o resgate de empreendimentos considerados importantes, como a Fábrica Nacional de Motores, a Companhia Vale do Rio Doce e a Companhia Nacional de Álcalis (BRASIL, 1978, p. 83-84).

O ano de 1949 é analisado na carta de 15 de março de 1950. Os portos receberam investimentos, como no caso do Rio de Janeiro, que teve seu cais ampliado, equipamentos renovados e melhorias de acesso a navios de grande porte - inclusive petroleiros já comprados pelo governo para aumentar a frota marítima brasileira. Essa aquisição era vista como estratégica, porque geraria economia de divisas e permitiria adquirir maior quantidade de derivados de petróleo, além de 
garantir o abastecimento em óleo cru das refinarias e a distribuição dos seus produtos na cabotagem (BRASIL, 1978, p. 111).

O desenvolvimento da indústria petrolífera refletia-se, também, através da instalação de refinarias como a de Mataripe, com produção estimada, à época, de 2.500 barris diários, e com projeto para a criação de outra com capacidade para até 45.000 barris diários. A partir daí se alavancavam outros empreendimentos, como o oleoduto Santos-São Paulo - considerado referência de partida para o desenvolvimento da política petrolífera brasileira. A questão energética era considerada primordial para as bases do progresso industrial, tanto que o governo também havia apoiado o Plano de Eletrificação do Rio Grande do Sul.

A análise da mensagem de 1950 é feita na obra $O$ governo Dutra: algumas realizações, diretrizes doutrinárias, um período de paz (1956), de José Teixeira de Oliveira. Nela, Dutra refere-se a diversos momentos marcantes de seu mandato, discorrendo sobre as principais realizações do governo. Exalta o crescimento na produção de energia elétrica de 33\%, entre 1945-1948, média que saltou para 44\% no ano seguinte (DUTRA apud OLIVEIRA, 1956, p. 25), além da realização de obras públicas consideradas importantes para o desenvolvimento industrial. Com relação à educação, "[...] foram construídos edifícios para seis escolas industriais e fizeram-se melhoramentos em outras sete" (DUTRA apud OLIVEIRA, 1956, p. 27). Esse investimento no ensino industrial corrobora a ideia de uma economia calcada na expansão desse setor de forma planejada pelo governo, que iniciou a construção de escolas em Fortaleza, Natal, Florianópolis, Cuiabá, João Pessoa e Belo Horizonte, além da reforma de escolas em outras capitais, bem como a modernização de oficinas e laboratórios, despendendo cerca de $\mathrm{Cr} \$ 16$ milhões (DUTRA apud OLIVEIRA, 1956, p. 69).

Outro exemplo do dirigismo econômico em favor da indústria é a lei $\mathrm{n}^{\circ} 650$, de 13 de março de 1949, considerada a "[...] lei mais importante do ano [...] que autorizou a abertura de crédito especial para aquisição de locomotivas, refinarias e navios petroleiros" (DUTRA apud OLIVEIRA, 1956, p. 39). Também na mineração, o governo orientou e incentivou o aproveitamento das jazidas através de análises, pesquisas laboratoriais e fiscalização do cumprimento do Código de Minas vigente. A interferência estatal manifestou-se com "[...] as melhorias introduzidas na indústria carbonífera nacional e que se realizam nos estados do Rio Grande do Sul, Paraná e Piauí." (DUTRA apud OLIVEIRA, 1956, p. 106).

O Nordeste do Brasil despertava especial interesse na equipe econômica e o seu desenvolvimento era considerado crucial para a transformação da economia e a descentralização da produção, aproveitando a oferta de recursos naturais e mão de obra.

A aplicação maciça de investimentos no plano geral de desenvolvimento do Nordeste poderá mesmo transformar o panorama econômico-finan- 
ceiro do país, com a ampliação das potencialidades do mercado interno e o fortalecimento da sua capacidade produtiva. Sobre constituir o início de um ciclo de descentralização - cada vez mais exigida pela segurança nacional - a industrialização do Nordeste virá corrigir o histórico desnivelamento oriundo da concentração de iniciativas e investimentos nas áreas meridionais do país. [...] A industrialização do Nordeste, inclusive nos domínios da eletroquímica e da eletro metalurgia, está à vista, qual nova força estimulante e renovadora de toda a estrutura econômico-financeira da nacionalidade (DUTRA apud OLIVEIRA, 1956, p. 115-116, grifo nosso).

As expressões grifadas na citação direta retratam a forma como o governo Dutra concebia a atuação do Estado na economia. Há um claro interesse do governo em participar ativamente das transformações socioeconômicas no Brasil - dando continuidade ao processo de substituição de importações - em que o Estado induz a industrialização (inclusive buscando descentralizar a atividade), mostrando-se atento a aspectos que pudessem interferir nos interesses nacionais.

O intervencionismo estatal do período atinge seu ponto mais visível no controle de importações que visava "[...] disciplinar seu comércio externo, o que o fez graças à Lei no 262, de 23 de fevereiro de 1948 [...]" (DUTRA apud OLIVEIRA, 1956, p. 125). Diante da crise no balanço de pagamentos, o governo não optou pela liberalização cambial, que seria, em tese, mais coerente com uma postura ortodoxa. Há vários motivos para isso, desde a indisposição de romper com o acordo de Bretton Woods até o temor por possível inflação que representaria a depreciação abrupta do câmbio. Entretanto, nota-se que o governo não apenas manteve a taxa fixa de câmbio (no patamar de $\mathrm{Cr} \$ 18,50$ por dólar), mas estabeleceu que as importações, a partir de então, dependeriam de licenciamentos a serem coordenados pela Carteira de Exportação e Importação (Cexim). O critério de licenciamento dependeria da essencialidade dos bens, a qual os classificava em cinco faixas - explicitamente um critério político deliberado em favor da industrialização substitutiva, pois colocava, nas primeiras faixas, os bens de capital e intermediários necessários à indústria, enquanto os bens de consumo, "supérfluos" ou já atendidos pela indústria nacional eram arrolados nas faixas restantes. A ordem da essencialidade exposta na Lei $\mathrm{n}^{\circ} 842$ de 1949, que prorrogava a Lei original $\mathrm{n}^{\circ} 262$ de 1948 por dois anos, colocava como artigos essenciais combustíveis e lubrificantes, alimentos de primeira necessidade, matérias-primas, máquinas e equipamentos para a indústria nacional, cimento e aparelhos científicos.

Como Furtado (1977, p. 218) assinala em Formação econômica do Brasil, o "[...] setor industrial era assim favorecido duplamente: por um lado, porque a concorrência externa se reduziria ao mínimo através do controle das importações: por outro, porque as matérias-primas e os equipamentos podiam ser adquiridos a preços relativamente baixos". Assim, é visível que as medidas procuraram administrar a crise cambial não só sem prejudicar a substituição de importações, mas 
incrementando-a, e não apenas por favorecer a importação dos "essenciais": ao colocar os bens duráveis e "supérfluos" nas faixas de IV e V, acabava por dificultar sua compra no exterior e, com isso, criar condições para que a demanda fosse atendida por futura produção doméstica. Pode-se afirmar, em decorrência, que a substituição de importações ocorrida no período de Kubitschek, a qual avança para setores como a indústria eletroeletrônica e automobilística, tem como uma de suas causas as condições efetivas criadas na política cambial do governo Dutra (ou, caso se queira, um "subproduto" dela).

Na Tabela 2, os dados acerca da indústria de transformação mostram que o produto efetivo cresceu, em média, 9,4\% ao ano, saltando de $\mathrm{Cr} \$ 32,3$ milhões para Cr\$ 50,8 milhões entre 1946 e 1951. Nesse mesmo período, a capacidade utilizada chegou a $92 \%$.

Tabela 2 - Indústria de transformação de produto efetivo e potencial (Cr\$ milhões de 1949)

\begin{tabular}{cccc}
\hline Ano & $\begin{array}{c}\text { Produto } \\
\text { efetivo }\end{array}$ & $\begin{array}{c}\text { Produto } \\
\text { potencial }\end{array}$ & $\begin{array}{c}\text { Capacidade } \\
\text { utilizada (\%) }\end{array}$ \\
\hline 1946 & 32,34 & 38,41 & 84 \\
1947 & 33,46 & 41,31 & 81 \\
1948 & 36,75 & 44,43 & 83 \\
1949 & 40,38 & 47,79 & 84 \\
1950 & 45,95 & 51,39 & 89 \\
1951 & 50,76 & 55,27 & 92 \\
1952 & 53,29 & 59,45 & 90 \\
\hline
\end{tabular}

Fonte: Malan (1980, p. 318).

Outra política que resultou no fomento à industrialização foi o crédito destinado ao setor. A participação dos empréstimos direcionados para a indústria cresceu largamente durante o governo Dutra. Em 1946, a indústria de transformação representava $17,4 \%$ do total da carteira do Banco do Brasil, enquanto que, em 1951, o valor já era de 29,4\%. Nesse contexto, a agricultura perdeu participação na destinação de crédito, conforme se observa na Tabela 3. Com relação à evolução dos valores nominais, a concessão de crédito para a indústria cresceu, em média, $34 \%$ ao longo do período. 
Tabela 3 - Empréstimos concedidos pelo Banco do Brasil por setor (1946-1952)

\begin{tabular}{cccc|ccc}
\hline & \multicolumn{3}{c}{ Agricultura } & \multicolumn{3}{c}{ Indústria } \\
\cline { 2 - 7 } Ano & $\begin{array}{c}\text { Empréstimos } \\
\text { reais } \\
\text { (Cr\$ milhões } \\
\text { de 1939) }\end{array}$ & $\begin{array}{c}\text { Partici- } \\
\text { pação } \\
\text { da agri- } \\
\text { cultura } \\
(\%)\end{array}$ & $\begin{array}{c}\Delta \% \\
\text { Nominal } \\
\text { (agricul- } \\
\text { tura) }\end{array}$ & $\begin{array}{c}\text { Partici- } \\
\text { Empréstimos } \\
\text { reais } \\
\text { (Cr\$ milhões } \\
\text { de 1939) }\end{array}$ & $\begin{array}{c}\text { paço da } \\
\text { indústria } \\
\text { de trans- } \\
\text { formação } \\
(\%)\end{array}$ & $\begin{array}{c}\Delta \% \\
\text { Nominal } \\
\text { (indústria } \\
\text { de transfor- } \\
\text { mação) }\end{array}$ \\
\hline 1946 & $1.749,6$ & 52,9 & $-8,7$ & 589,0 & 17,4 & 12,9 \\
1947 & $1.433,9$ & 45,4 & $-8,6$ & 814,3 & 19,7 & 20,5 \\
1948 & $1.231,6$ & 39,9 & $-1,6$ & 966,8 & 22,7 & 29,0 \\
1949 & $1.154,3$ & 40,7 & 23,6 & $1.240,8$ & 24,5 & 30,9 \\
1950 & $1.229,1$ & 42,0 & 19,1 & $1.301,4$ & 25,6 & 20,5 \\
1951 & $1.410,3$ & 32,7 & 29,4 & $2.216,8$ & 29,4 & 90,7 \\
1952 & $1.708,2$ & 32,7 & 39,5 & $3.349,9$ & 33,3 & 58,0 \\
\hline
\end{tabular}

Fonte: Elaboração própria a partir de Malan (1980).

Ao se analisar os valores em termos reais, a tendência verificada na Tabela 3 se mantém. Enquanto os valores para a agricultura decresceram entre $1946 \mathrm{e}$ 1951, o crédito real à indústria, que era de Cr\$ 589 milhões, em 1946, alcançou Cr\$2.217 milhões, em 1951 - perfazendo um crescimento médio anual de 30,4\%.

As análises anteriores, os trechos transcritos e os dados apresentados elencaram diversos elementos e argumentos que sustentam o interesse do governo em continuar participando ativamente da vida econômico-social brasileira e promovendo o aprofundamento do PSI. Sendo assim, há inúmeros indícios que apontam para uma tentativa de fomento de investimentos ou criação de ambiente institucional a favor por parte do Estado, com foco na industrialização, caracterizando uma política econômica desenvolvimentista, principalmente através do licenciamento de importações e do crédito direcionado à indústria.

\section{A Associação ao Capital Externo e o Novo Estilo de Desenvolvimento}

Após a caracterização do governo Dutra como desenvolvimentista, é possível aprofundar o debate e, à luz da tipologia antes mencionada, associá-lo a um subtipo de desenvolvimentismo, qual seja, ao dependente associado. Deve-se, para tanto, ter-se presente a conjuntura internacional da época, que era diferente da do período Vargas e procurava colher os frutos da participação do Brasil durante a guerra, quando o país se colocou como principal aliado latino-americano dos Estados Unidos. O governo almejava, assim, suprir, com recursos do exterior, boa parte dos investimentos necessários para alavancar a indústria nacional, uma vez 
que internamente havia uma limitação das possibilidades de investimento, tanto por parte do Estado, quanto do setor privado.

É nesse ponto que a literatura argumenta que o governo fora iludido pelas reais pretensões de investimento norte-americano no país e que tenha obtido nada mais do que um relatório com sugestões de políticas produzido pela Missão Abbink. Almeida (1993) alude que a política externa dos Estados Unidos buscava criar condições para facilitar a entrada de capitais no país, mas não colocava o Brasil em posição privilegiada em relação aos outros países latino-americanos. $\mathrm{Na}$ conjuntura internacional, esperava-se uma alta nos preços do café, especialmente após a eliminação do preço-teto estipulada pelo governo dos Estados Unidos em meados de 1946. Cerca de $40 \%$ das exportações eram destinadas a países de moedas inconversíveis ou bloqueadas, e o café representava aproximadamente $70 \%$ das exportações para áreas de moedas conversíveis (VIANNA; VILLELA, 2005). Vianna (1990) considera que as autoridades foram vítimas da "ilusão de divisas" e que o combate à inflação fora intensificado porque os investimentos que o governo não poderia fazer seriam supridos por recursos externos favorecidos por uma política liberal de câmbio que também corrigiria o desequilíbrio do balanço de pagamentos.

Apesar das ponderações dos autores, considera-se que não é possível relegar a associação ao capital estrangeiro somente ao relatório produzido pela Missão Abbink (1948), quando técnicos norte-americanos analisaram os principais gargalos ao crescimento da economia brasileira. É importante salientar que esse diagnóstico considerava a participação do Estado como fundamental para promover o desenvolvimento nacional (SARETTA, 2000). Da mesma forma, Skidmore (1976, p. 100) aponta que "[...] o relatório dava ênfase às sérias deficiências nas áreas de transporte e de energia, e reconhecia que estas áreas de estrangulamento iriam requerer vigorosa ação estatal".

Destarte, há evidências no sentido de mostrar que, mesmo em menor magnitude do que o governo previa ou gostaria que ocorresse, o capital estrangeiro, principalmente o norte-americano, foi importante fonte de financiamento para o desenvolvimento industrial durante o governo Dutra, sendo que essa associação foi estimulada e perseguida pelo governo. Um trecho retirado do Diário Oficial da União de março de 1947 exemplifica tal fato:

Em matéria de crédito internacional, observa-se o deslocamento dos empréstimos por parte dos particulares para os Governos ou instituições internacionais. A redução de créditos particulares aos Governos estrangeiros decorre da manifesta preferência aos investimentos diretos. A entrada de capitais estrangeiros no território nacional, para variados empreendimentos, tende a ser cada vez maior. Com o propósito de facilitar o afluxo desses capitais, o Governo baixou o decreto-lei $n^{\circ}$ 9.025, de 27 de fevereiro do ano passado, assegurando a remessa de lucros e o retorno de capitais. Abrimos as portas ao capital alienígena sempre que ele 
possa colaborar ativamente na exploração racional de nossos recursos naturais, no aperfeiçoamento de nossas instalações técnicas, na criação de novas indústrias, e continuaremos esta política com as precauções necessárias para que essa colaboração seja de fato benéfica à economia nacional (DUTRA, 1947, p. 1).

O referido Decreto-Lei $\mathrm{n}^{\circ} 9.025$ regulamentava o retorno de capitais estrangeiros e as operações de crédito. Através dele, o governo sinalizava assegurar o retorno dos investimentos desde que a parcela anual não ultrapassasse $20 \%$ do capital registrado na Carteira de Câmbio do Banco do Brasil. Além disso, os recursos que ficassem aplicados por no mínimo dois anos em títulos da dívida pública ou outra renda fixa estariam liberados para transferência integral e sem restrições. Outro ponto abordado no decreto era a remessa de juros, lucros e dividendos, que não poderia superar $8 \%$ do capital registrado.

Além dessas medidas, também pode-se considerar o posicionamento de dirigentes brasileiros durante a reunião de Genebra em 1947. Segundo Almeida (1993), a comitiva nacional defendia a ajuda externa através de empréstimos governamentais para apoiar os esforços industrializantes do país - o "interesse nacional" de industrialização estava entre as prioridades; admitia-se que os capitais privados internos, sozinhos, não teriam capacidade de suprir as "necessidades de desenvolvimento". Baer (1966) salienta, porém, que, a despeito das propostas, a fragilidade do balanço de pagamentos dificultava a tomada de recursos no exterior.

O relatório da Missão Abbink considerava importantíssimo que o Brasil resolvesse o problema da inflação, pois essa era uma medida que tinha relação direta com a atração de investimentos do exterior, já que entendia haver uma enorme disparidade entre o poder de compra interno e externo, desestimulando o ingresso de recursos. Por outro lado, o "excesso de nacionalismo" começara a ser resolvido através da Constituição de 1946, considerada mais liberal que a anterior, de 1937. Sendo assim, os obstáculos mais complicados eram a inflação e o desequilíbrio no comércio externo, e as principais recomendações eram:

a) eliminação dos atrasados comerciais com outros países;

b) controle das importações e do câmbio para garantir as remessas, a pronta conversão e o reforço nas reservas de contingência;

c) convênios para evitar bitributação; e

d) mudanças na legislação e regulamentação sobre remessas de lucros e transferências de capital (MALAN, 1980, p. 54-55).

É notável o interesse do governo em honrar os atrasados comerciais. Dutra refere-se a tal postura como um importante feito de seu mandato, que visava, sobretudo, melhorar a imagem do Brasil no exterior, variável relevante para atrair investimentos. A busca de uma solução para as contas externas através da conta 
capital iniciara com a política de câmbio liberal, que não se opunha às saídas de capital, ao mesmo tempo que almejava promover ingressos mais consistentes de recursos.

A Tabela 4 mostra estimativas do estoque de capital norte-americano. É possível verificar que os valores cresceram de forma intensa, em média $21 \%$ ao ano entre 1946 e 1952. O destaque fica para a indústria de transformação, a qual representou metade do total em 1952, sendo que esse montante correspondia a cerca de um terço do total em 1946. Cabe ressaltar, ainda, a indústria petrolífera, que triplicou seu estoque de capital no mesmo período.

Tabela 4 - Estimativas do estoque de capital norte-americano no Brasil (em US\$ milhões)

\begin{tabular}{lccccc}
\hline Setor & $\mathbf{1 9 4 0}$ & $\mathbf{1 9 4 3}$ & $\mathbf{1 9 4 6}$ & $\mathbf{1 9 5 0}$ & $\mathbf{1 9 5 2}$ \\
\hline Indústria de transformação & 70 & 66 & 126 & 284 & 513 \\
Petróleo (distribuição) & 31 & 30 & 45 & 112 & 173 \\
Serviços públicos & 112 & 88 & 125 & 138 & 151 \\
Comércio & 18 & 29 & 27 & 110 & 176 \\
Outros & 9 & 20 & - & - & - \\
\hline Total & $\mathbf{2 4 0}$ & $\mathbf{2 3 3}$ & $\mathbf{3 2 3}$ & $\mathbf{6 4 4}$ & $\mathbf{1 0 1 3}$ \\
\hline
\end{tabular}

Fonte: Malan (1980, p. 181).

A análise dos discursos presidenciais também referenda a hipótese de que o governo Dutra contava com a associação do capital estrangeiro para incrementar o desenvolvimento. Em discurso na Bahia, ao visitar o Vale do Rio São Francisco, em 1947, o presidente ressaltava a importância das obras contra as secas realizadas por iniciativas estrangeiras no Vale do Tennessee (BRASIL, 1948a). Em outra fala no Palácio do Catete, também em 1947, Dutra ressalta o compromisso do Brasil com a defesa do continente e que pretendia manter-se fiel nessa conduta, de forma a manter boas relações de intercâmbio econômico (BRASIL, 1948a).

Na mensagem enviada ao Congresso em 1950, Dutra destaca vários acontecimentos do seu governo com atenção para os negócios realizados com o exterior e ações diplomáticas. Durante a visita aos Estados Unidos em 1947, quando teve a oportunidade de conferenciar com o presidente Truman, foram tratadas oportunidades de negócios bilaterais e o fortalecimento das ações regionais no continente para o desenvolvimento econômico-social. Na continuação da mensagem, os investimentos externos possuem participação nas necessidades de infraestrutura do Brasil. No Plano de Eletrificação do Rio Grande do Sul, o governo federal colaborou nas negociações para obtenção de financiamento em moeda estrangeira para aquisição de equipamentos. Nos transportes, as ferrovias receberam melhorias nos sistemas de sinalização, como novos materiais e 90 novas locomotivas contrata- 
das junto à indústria francesa. A indústria petrolífera expandiu seus negócios com "[...] a aquisição de uma frota de petroleiros a ser construída em estaleiros suecos, ingleses, holandeses e japoneses" (DUTRA apud OLIVEIRA, 1956, p. 123). Mais realizações nesse setor são exaltadas neste trecho:

Das refinarias, a de Mataripe (2.500 barris diários) está sendo montada e será inaugurada no dia 7 de setembro do corrente ano. Para a de 45.000 barris diários, já foram firmados, pelo Conselho Nacional do Petróleo, os contratos para a feitura do projeto e para a sua construção, aquele com uma firma americana e este com um consórcio francês (DUTRA apud OLIVEIRA, 1956, p. 123).

Os argumentos mostrados nesta seção corroboram a ideia de que a contribuição estrangeira foi muito além do Relatório Abbink. Efetivamente, o governo buscou fortalecer laços com o exterior, em especial com os Estados Unidos, além de uma participação mais ativa das relações externas do país. Lograram-se, inclusive, acordos para a realização de intercâmbios de pessoas para a troca de experiências no setor público (administração pública, saúde), bem como a obtenção de mão de obra mais qualificada, que se entendia como necessária, principalmente, com o avanço da industrialização, conforme destacado por Dutra em suas mensagens ao congresso.

Ao tratarmos do Relatório Abbink, o governo encampou diversas medidas sugeridas pelos técnicos, inclusive com o ataque à inflação de forma a aumentar a credibilidade do país e conseguir atrair os investimentos almejados. Formou-se na literatura a ideia, como a de Baer (1966) antes mencionada, de que os Estados Unidos não investiram no país tudo que o governo esperava após a guerra, dado o papel exercido pelo Brasil durante o confronto. Esse conflito entre pretensão e realização pode até ser verdade. Entretanto, os dados da Tabela 4 realçam o forte incremento de capital norte-americano instalado no Brasil, com destaque para a indústria de transformação. Entre outras realizações associadas a recursos externos, exaltadas em discursos ou mensagens, boa parte delas está ligada a empreendimentos de infraestrutura, os quais serviriam para dotar diversas regiões do interior do país de ligação com uma rede de transportes e energia, sendo esses os pilares para o desenvolvimento da indústria em outras regiões. Logo no segundo ano do governo já foram adotadas medidas para atrair capital, conforme relatado pelo próprio presidente em 1947, quando se referia ao Decreto-Lei $n^{\circ}$ 9.025, que almejava dar maior previsibilidade aos investidores estrangeiros quanto ao tratamento de seu capital e especificava as regras para retorno de recursos: "[...] As múltiplas medidas tomadas no tocante à política cambial, inspiradas todas no objetivo de facilitar e normalizar nosso intercâmbio com o estrangeiro, concorreram para consolidar o valor do cruzeiro nos mercados financeiros do exterior" (BRASIL, 1948b, p. 110-111). 
A citação deixa claro que a política econômica externa rapidamente buscou angariar incentivos para a entrada de capitais no país. O objetivo era demonstrar a existência de regras claras e seguras que garantissem o retorno dos investimentos aos estrangeiros. Posteriormente, foram adotadas novas medidas com o passar do governo, quando o quadro de liberalização cambial deu lugar ao câmbio fixo e com controle de importações. Porém, esse também pode ser considerado um movimento do governo na tentativa de proteger suas divisas para importações consideradas essenciais, além de garantir o fornecimento de dólares para as remessas do capital estrangeiro. Todos esses fatos conjuntamente permitem robustecer a hipótese de que o estilo ou padrão do desenvolvimentismo de Dutra afasta-se do "nacional desenvolvimentismo" de Vargas, pois apostava menos no Estado e mais no capital estrangeiro como fator indutor. Deve-se deixar claro que ambos os subtipos de desenvolvimentismo não excluem nem o Estado, nem o capital estrangeiro: o que os difere é fundamentalmente o grau e o papel de cada um deles na consecução do projeto desenvolvimentista. 


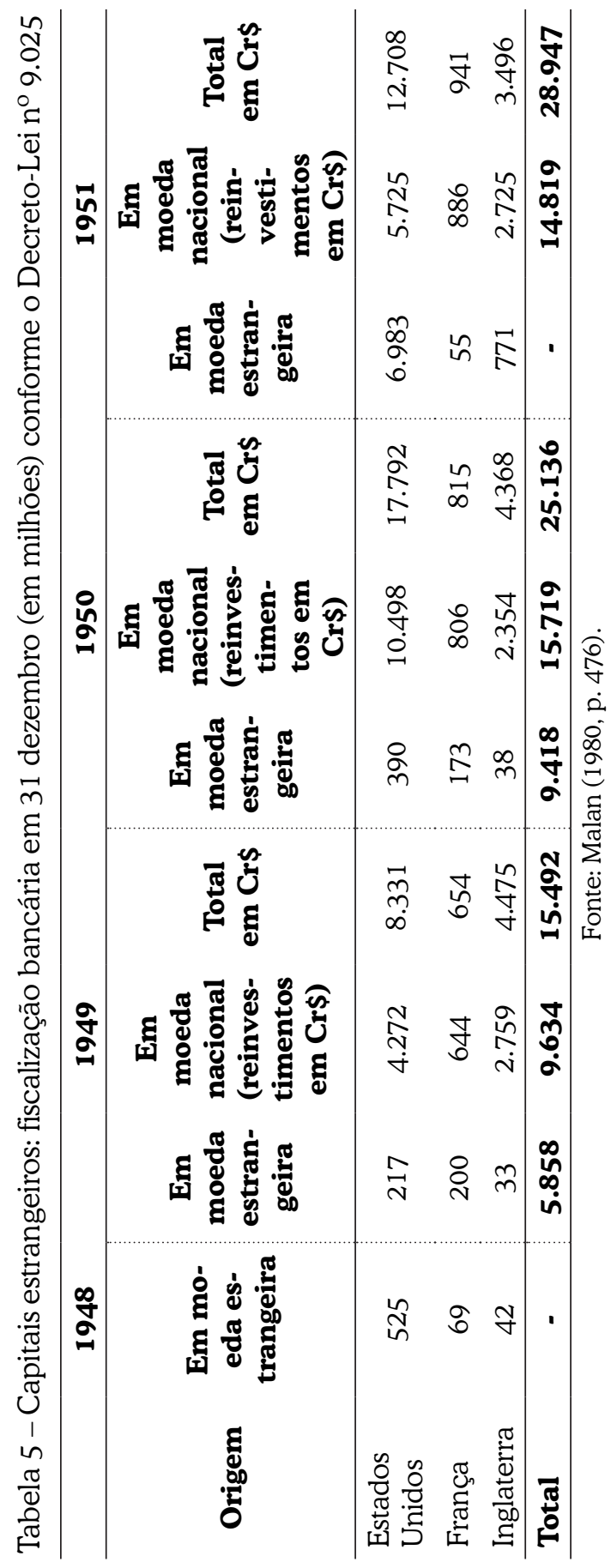


Os dados da Tabela 5 concluem esta seção e ajudam a corroborar a defesa da associação do governo Dutra com o capital externo para a promoção da industrialização no Brasil e o fomento do desenvolvimento econômico - mesmo diante das restrições estabelecidas pela conjuntura internacional da época, que impunha o foco, especialmente norte-americano, na reconstrução europeia e japonesa. Os dados a seguir mostram o movimento líquido de capitais privados com maturação de longo prazo. Apesar do valor negativo em 1951, os cinco anos anteriores registraram cifras positivas com uma média de US $\$ 29$ milhões ao ano, entre 1946 e 1950, sendo o ápice registrado, em 1948, com US $\$ 47,7$ milhões (MALAN, 1980, p. 188).

Os capitais estrangeiros submetidos ao Decreto-Lei $n^{\circ} 9.025$ foram contabilizados em termos de moeda estrangeira e reinvestimentos, conforme a Tabela 5. Ao serem selecionados os principais países (Estados Unidos, França e Inglaterra), constata-se um expressivo aumento quando o total, em Cr\$, alcançou 28,9 milhões, em 1951, ante os Cr\$15,4 milhões, em 1949 - sendo boa parte desse montante proveniente de reinvestimentos.

\section{Considerações Finais}

Pode-se concluir, diante do exposto, que é um equívoco associar a política econômica do governo Dutra a liberalismo ou ortodoxia. Embora medidas com esse caráter tenham sido adotadas, principalmente no primeiro ano de mandato, não foram mantidas ao longo do período governamental. Ao contrário, todas as evidências sugerem a pertinência da primeira hipótese deste estudo, que o associa a desenvolvimentismo e, desse modo, como uma continuidade de apoio à industrialização substitutiva de importações começada por Vargas na década de 1930.

Da mesma forma, o material empírico utilizado aponta na direção de tipificar a política econômica do período como bastante próxima ao desenvolvimentismo dependente associado, em oposição do nacional-desenvolvimentismo de Vargas do período precedente. O governo Dutra dá mostras de perceber uma conjuntura internacional favorável a investimentos e financiamentos externos e, com respaldo de setores empresariais do país que pressionavam por apoio estatal à industrialização e a investimentos em infraestrutura, aposta num estilo ou padrão de desenvolvimento com maior presença e alavancagem de capital estrangeiro - numa conjuntura bastante diversa do primeiro governo de Vargas, já que este enfrentou inicialmente as turbulências da Grande Depressão e, posteriormente, as da Segunda Guerra. Nota-se a sequência de pronunciamentos oficiais nesse sentido, a robustecer a interpretação de que havia intenção deliberada nesse sentido. Mais que isso, os Estados Unidos se mostraram como principal fonte de investimentos externos do país, e a indústria de transformação, bem como diversas obras de 
infraestrutura foram alavancadas por esses recursos. Medidas como o Decreto-Lei $n^{\circ} 9.025$ ressaltam o interesse do governo em estabelecer bases institucionais para atrair recursos do exterior. Também a política cambial com licenciamento por faixas não deixa dúvida quanto a sua intencionalidade. O próprio combate à inflação - que poderia prima facie ser entendido linearmente como manifestação de ortodoxia, ancora-se no discurso da necessidade de transmitir confiança e credibilidade aos investidores para incrementar o crescimento, inclusive industrial, além de garantias para remessas de recursos e de pagamento dos atrasados comerciais.

Tal postura francamente favorável à integração da economia nacional, mormente de sua indústria, à hegemonia norte-americana do pós-guerra, foi equivocadamente vista por parte da literatura e dos próprios coevos como expressão de liberalismo econômico e rompimento total com o projeto varguista, quando, na verdade, tratava-se de ruptura apenas parcial com relação a este, pois mantinha a proposta desenvolvimentista de industrializar o país, embora sob novas bases. A política econômica de Dutra, assim, antecipa ou prenuncia outro estilo, padrão ou subtipo de desenvolvimento: o dependente-associado, o qual aflorou de forma mais típica no governo de Juscelino Kubitschek e foi mantido após 1964.

\section{Referências}

ABREU, M. P. (Org.). A ordem do progresso: cem anos de política econômica republicana, 1888-1989. Rio de Janeiro: Campus, 1990.

ALMEIDA, P. R. Os limites do alinhamento: liberalismo econômico e interesse nacional. Estudos Ibero-Americanos, Porto Alegre, v. 19, n. 1, p. 13-39, jul. 1993.

AREND, M. 50 anos de industrialização do Brasil (1955-2005): uma análise evolucionária. 2009. 251 f. Tese (Doutorado em Economia) - Programa de Pós-Graduação em Economia, Universidade Federal do Rio Grande do Sul, Porto Alegre, 2009.

BAER, W. A industrialização e o desenvolvimento econômico no Brasil. Rio de Janeiro: Fundação Getúlio Vargas, 1966.

BASTOS, P. P. Z. Liberal esclarecido ou aliado fiel? Sobre a natureza política econômica externa brasileira no governo Dutra (1946-1951). Revista Economia, Brasília, DF, v. 11 , n. 4, p. 285-320, dez. 2010. Disponível em: <http://www.anpec.org.br/revista/vol11/ vol1 1n4p285_320.pdf>. Acesso em: 12 out. 2016.

. O presidente desiludido: a campanha liberal e o pêndulo de política econômica no governo Dutra (1942-1948). História econômica e história de empresas, São Paulo, v. 7, n. 1, p. 99-135, jan./jun. 2004. Disponível em: <http://hs.unb.br/revistaabphe/index.php?journal $=$ rabpheÉpage $=$ article $\mathcal{E}$ op $=$ viewËpath $\% 5 \mathrm{~B} \% 5 \mathrm{D}=170 \mathcal{E}$ path\%5B $\% 5 \mathrm{D}=133>$. Acesso em: 10 out. 2016.

BRASIL. Biblioteca da Presidência da República. Gaspar Dutra: discursos e alocuções proferidos em 1947 pelo presidente Eurico G. Dutra. Brasília, DF: Imprensa Nacional, 1948a. 
Disponível em: < http:/www.biblioteca.presidencia.gov.br/publicacoes-oficiais/catalogo/ gaspar-dutra >. Acesso em: 22 set. 2016.

BRASIL. Câmara dos Deputados. Mensagens presidenciais: 1947-1964. Eurico Gaspar Dutra: 1947-1950. Brasília, DF: Centro de Documentação e Informação, 1978. p. 29-122.

. Senado Federal. Anais do Senado: sessões de março e abril de 1947. Rio de Janeiro: Imprensa Nacional, v. 5, 1948b. Disponível em: < http://www.senado.leg.br/publicacoes/ anais/pdf/Anais_Republica/1947/1947\%20Livro\%202.pdf>. Acesso em: 22 set. 2016.

BRESSER-PEREIRA, L. C. Desenvolvimento e crise no Brasil: história, economia e política de Getúlio Vargas a Lula. São Paulo: Editora 34, 2003.

CARDOSO, F. H. Política e desenvolvimento em sociedades dependentes. Rio de Janeiro: Zahar, 1971.

CARONE, E. A quarta república (1945-1964). São Paulo: Difel Difusão, 1980.

CUNHA, T. Realidade econômica e a carta de Teresópolis. Rio de Janeiro: Atlas, 1946.

DUTRA, E. G. Créditos no exterior. In: BRASIL. Diário Oficial [da] República Federativa do Brasil, Poder Executivo, Brasília, DF, 17 mar. 1947. Seção 1, n. 3531. Disponível em: $<$ http://www.jusbrasil.com.br/diarios/2254363/pg-35-secao-1-diario-oficial-da-uniaodoude-17-03-1947/pdfView>. Acesso em: 22 set. 2016.

FONSECA, P. C. D. Desenvolvimentismo: a construção do conceito. In: CALIXTRE, B.; BIANCARELLI, A. M.; CINTRA, M. A. Presente e futuro do desenvolvimento Brasileiro. Brasília, DF: IPEA, 2014. Disponível em: <http://www.ipea.gov.br/portal/index.php?option=com contentEview $=$ articleĖid $=2580>$. Acesso em: 22 set. 2016 .

. Nem ortodoxia nem populismo: o segundo governo Vargas e a economia brasileira.

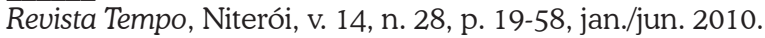

. Vargas: o capitalismo em construção. 2. ed. São Paulo: Brasiliense, 1999.

FURTADO, C. Formação econômica do Brasil. São Paulo: Editora Nacional, 1977.

LESSA, C. 15 anos de política econômica. Rio de Janeiro: Brasiliense, 1982.

MALAN, P. S. et al. Política econômica externa e industrialização no Brasil: 1939-1952. Rio de Janeiro: IPEA, 1980.

OLIVEIRA, J. T. (Ed.). O governo Dutra: algumas realizações, diretrizes doutrinárias, um período de paz. Rio de Janeiro: Civilização Brasileira, 1956.

PINTO, A. Notas sobre los estilos de desarrollo en América Latina. Revista Cepal, Santiago do Chile, n. 1, 1976.

SARETTA, F. Política econômica brasileira: 1946-1951. Araraquara: Cultura Acadêmica, 2000.

SKIDMORE, T. E. Brasil: de Getúlio Vargas a Castelo Branco, 1930-1964. Rio de Janeiro: Paz e Terra, 1976. 
TAVARES, M. C. Distribuição de renda, acumulação e padrões de industrialização. In: TOLIPAN, R.; TINELLI, A. C. A controvérsia sobre distribuição de renda e desenvolvimento. Rio de janeiro: Zahar, 1978. p. 36-72

VARGAS, G. A campanha presidencial. Rio de Janeiro: José Olympio, 1951.

VIANNA, S. B. A política econômica no segundo governo Vargas: 1951-1954. Rio de Janeiro: BNDES, 1987. (Prêmio BNDES de Economia).

. Política econômica externa e industrialização: 1946-51. In: ABREU, M. P. (Org.). A ordem do progresso: cem anos de política econômica republicana 1889-1989. Rio de Janeiro: Campus, 1990. p. 105-122

VIANNA, S. B.; VILLELA, A. O pós-Guerra (1945-1955). In: GIAMBIAGI, F.; VILLELA, A. (Org.). Economia brasileira contemporânea: 1945-2004. Rio de Janeiro: Elsevier, 2005. p. 21-44.

Recebido em: 05/11/2016.

Acesso em: 22/11/2016. 